\title{
PENGEMBANGAN APLIKASI SISTEM LAYANAN UNTUK JASA LAUNDRI BERBASIS WEB PADA ARBA SMILE LAUNDRY BANJARMASIN
}

\author{
Rusdina $^{1)}$, Fitrah Yuridka ${ }^{2}$ \\ ${ }^{1}$ Teknologi Informasi, Universitas Islam Kalimantan Muhammad Arsyad Al Banjari Banjarmasin \\ Email : russidina@gmail.com \\ ${ }^{2}$ Teknologi Informasi, Universitas Islam Kalimantan Muhammad Arsyad Al Banjari Banjarmasin \\ Email : yvitrah@yahoo.co.id
}

\begin{abstract}
ABSTRAK
Dalam kaitannya dengan majunya sebuah perusahaan, tentu tak lepas kaitannya dengan penggunaan teknologi yang mumpuni. Terutama perusahaan yang bergerak dibidang jasa seperti usaha pencucian Laundry. Mungkin selama ini ada beberapa Laundry yang sudah terkomputerisasi dalam hal pengelolaan data dan sebagainya. Untuk itu tujuan penelitian ini adalah membuat aplikasi yang dapat dipakai oleh Laundry yang selama ini masih belum terkomputerisasi dalam hal layanan. Penelitian ini menggunakan metode Studi Literatur yaitu dengan cara mengumpulkan dan menghimpun data dan informasi dari buku maupun internet yang berguna untuk pembelajaran dan pembuatan sistem yang akan dibuat. Tahap-tahap dalam penelitian ini yaitu; mengumpulkan data, perencanaan sistem, pembuatan sistem, dan tahap terakhir adalah pengujian sistem. Aplikasi yang digunakan dalam membangun sistem ini yaitu Dreamweaver, XAMPP sebagai localhost dan MySQL sebagai databasenya. Dalam hal ini sistem ini akan dilengkapi dengan sms gateway yang akan melengkapi semua yang dibutuhkan oleh perusahaan.
\end{abstract}

Kata Kunci : Sistem Layanan, Laundry, MySQL, PHP

\section{PENDAHULUAN}

Majunya sebuah perusahaan didukung dengan sistem manajemennya yang baik, mereka harus bisa memberikan kepuasan kepada pada konsumennya. Dan menjaga itu tidak mudah. Mereka harus senantiasa berinovasi untuk menciptakan kualitas yang optimal demi menjaga agar konsumen mereka tidak lari. Dan agar perusahaan mereka tetap bertahan ditengah ketatnya persaingan saat ini.

Layanan juga merupakan salah satu aspek penting dalam suatu perusahaan, penting bagi setiap pelaku bisnis, memberikan layanan yang maksimal. Khususnya pelaku bisnis dalam bidang jasa seperti Laundry.

Salah satunya adalah Arba Smile Laundry yang mana pada proses kegiatannya seharihari, Laundry ini melakukan kegiatan seperti pencatatan order customer, pencatatan data bahan dan material laundry seperti sabun, pewangi yang keluar dan masuk, lalu pencatatan data transaksi cucian yang sudah selesai. Sampai catatan oder antar dan jemput laundry untuk customer.

Sistem layanan yang berjalan saat ini masih menggunakan sistem yang manual dimana, kelamahan sistem yang manual menyebabkan tidak adanya keteraturan dalam pengelolaan data seperti, sulitnya menghitung berapa jumlah yang harus dibayar, berapa buah stok barang pendukung seperti pewangi maupun sabun pembersih. Bagaimana laporan perbulannya, sudah sesuai atau belum.

Maka dari itu diperlukan sebuah sistem yang dapat mengelola hal itu. Sehingga dipilihlah sebuah teknologi yang berbasis web dan tambahan sms gateway untuk pemberitahuan jika cucian telah selesai. 
a. Diagram konteks

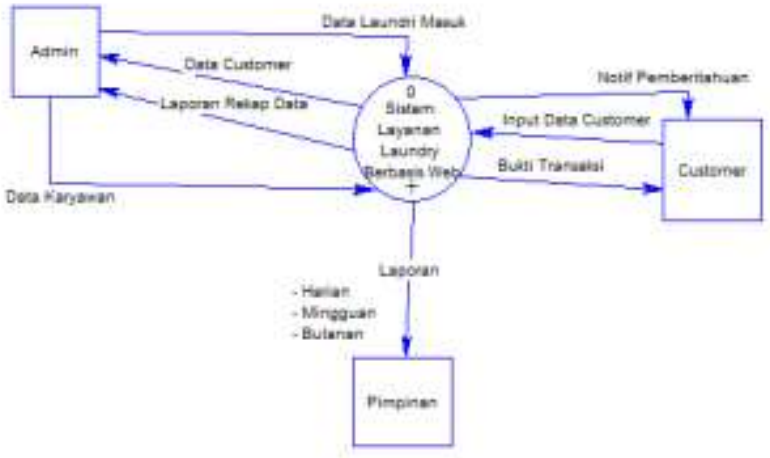

Gambar 1. Diagram Konteks Sistem Layanan Laundry

Pada gambar diagram diatas, admin bertugas menginput semua data yang diperlukan, consumer disini memberi memberikan identitas yang diperlukan untuk disimpan, costumer akan mendapatkan sejumlah nota pembayaran dan bukti transaksi. Untuk pimpinan mendapat laporan sesuai yang diperlukan.

b. Data Flow Diagram (DFD)

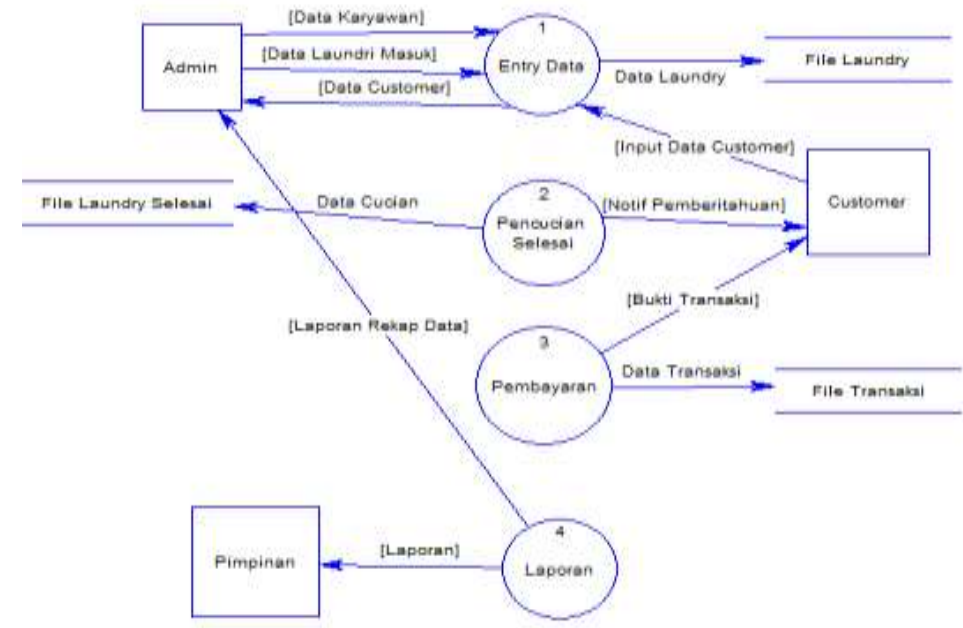

Gambar 2. DFD Level 0

\section{HASIL DAN PEMBAHASAN \\ 3.1. Tampilan Sistem}


Adapun hasil tampilan sistem aplikasi yang sudah dirancang oleh peneliti untuk perancangan jasa laundry berbasis web sebagai berikut :

1. Tampilan halaman login

Halaman login ini digunakan admin untuk login ke sistem. Dan admin sudah memiliki akun user dan passwordnya.

\section{Login}

acdruin

$\square$ Femember me

Masuk

Gambar 3. Halaman Login

2. Halaman Menu Utama

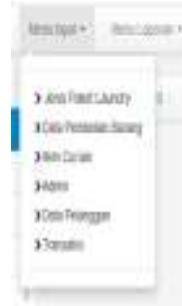

Gambar 4 Halaman Menu Utama

\section{Menu Transaksi}

Menu Transaksi digunakan untuk menghitung pembayaran untuk laundry yang dilakukan. Untuk menu transaksi, halaman yang akan ditampilkan adalah sebagai berikut :

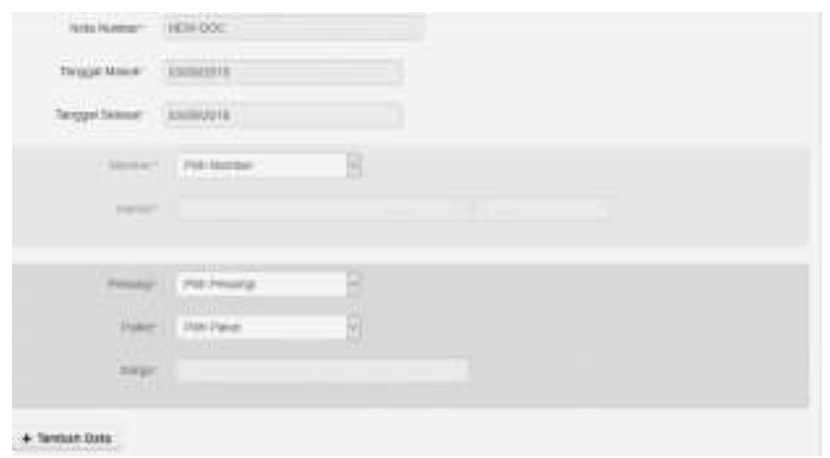

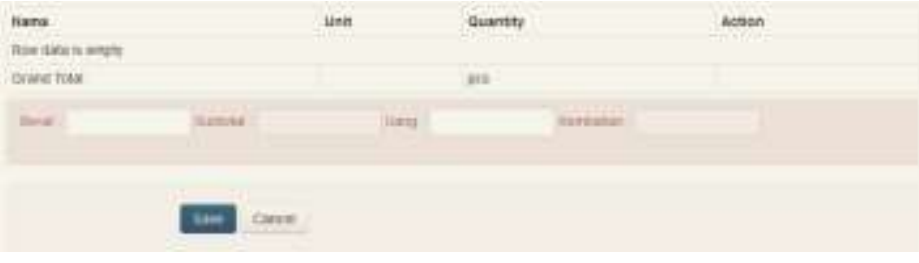

Gambar 5. Halaman Transaksi

4. Menu Pembelian Barang

Lalu data pembelian barang kebutuhan laundry adalah sebagai berikut :

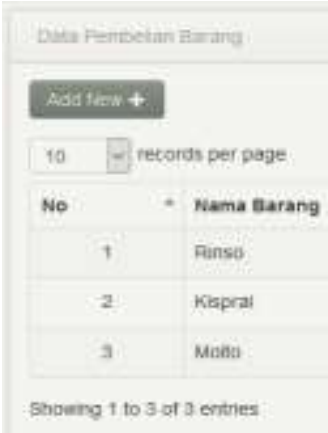

Gambar 6. Halaman Pembelian Barang

5. Menu Pelanggan

Menu Pelanggan digunakan untuk menambah pelanggan yang menggunakan jasa laundry. Untuk menu pelanggan tampilan halamannya sebagai berikut :

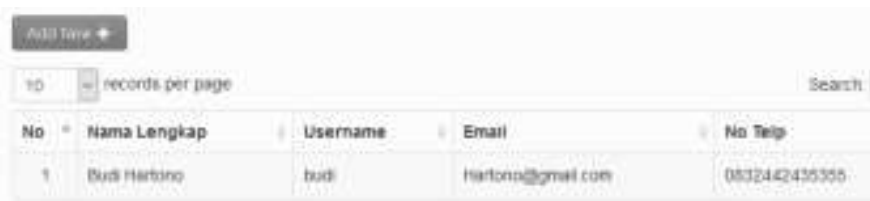

Gambar 7. Halaman Data Pelanggan

6. Menu Jenis Paket

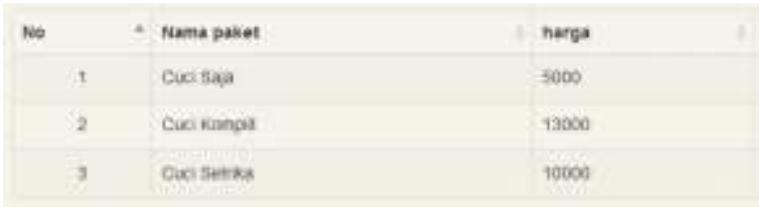

Gambar 8. Halaman Jenis Paket 


\begin{abstract}
Gambar di atas menggambarkan paket cucian apa saja yang dapat dipilih oleh pelanggan.
\end{abstract}

Adapun untuk tampilan sms gatewaynya adalah dalam bentuk sebagai berikut :

\section{Tampilan Kirim Pesan}

Untuk mengirimkan sms, tampilannya adalah sebagai berikut
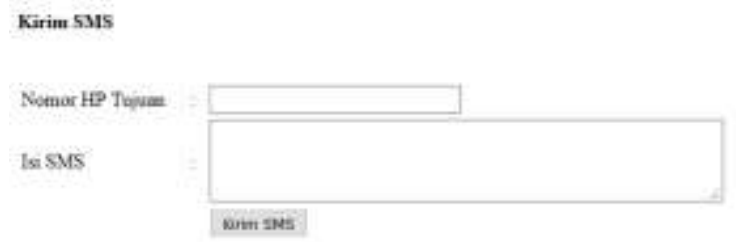

Gambar 9. Halaman Kirim Pesan

Pengiriman SMS ini bersifat satu arah, jadi pelanggan tidak bisa membalas pesan tersebut. Tujuan SMS Gateway ini adalah agar pelanggan tahu kapan cucian dapat diambil.

\section{KESIMPULAN}

Berdasarkan hasil yang didapatkan dalam penelitian ini, maka dapat dibuat beberapa kesimpulan sebagai berikut: Kelebihan Aplikasi system layanan laundry ini antara lain Aplikasi Layanan Laundry ini dapat memberi kemudahan bagi pimpinan untuk memonitoring aktivitas di Laundrinya. Aplikasi ini memudahkan seorang admin dalam melakukan transaksi setelah cucian selesai.Penambahan SMS Gateway dapat memberikan kepastian kepada pelanggan untuk mengambil cuciannya.

Diharapkan pada penelitian selanjutnya aplikasi ini dikembangkan dalam bentuk android atau dikembangkan dalam bentuk yang lebih baik.

\section{REFERENSI}

[1] Bayu,Aji. Pengertian Sistem \& Analisis Sistem, [pdf],

(http://bayuaji.staff.gunadarma.ac.id/Do wnloads/files/32090/Pengertian+Sistem $+\% 26+$ Analisis+Sistem.pdf, diakses tanggal 12 Juli 2017)

[2] Kadir, A., Konsep dan Tuntunan Praktis Basis Data, Andi, Yogyakarta, 1998.

[3] Kasiman, P. (2009). Aplikasi Web dengan $P H P$ dan MySQL. Yogyakarta: ANDI.

[4] Martin, J. (1990). Information Enginering Book II Planning and Analysis 2nd Edition. New Jersey: Prentice-Hall.

[5] Mulyana, Y.B., Trik Membangun Situs Menggunakan PHP dan MySQL, PT Elex Media Komputindo, Jakarta, 2004. 